\title{
Cigarette Staining and Cleaning of a Maxillofacial Silicone
}

\author{
R. YU, A. KORAN, C. N. RAPTIS, and R.G. CRAIG \\ The University of Michigan, School of Dentistry, Ann Arbor, Michigan 48109
}

In this study, a maxillofacial silicone elastomer was stained with cigarette smoke. The stain was then removed by solvent extraction using 1,1,1-trichloroethane. The cigarette smoke produced large color changes in the elastomer as measured from spectrophotometric reflectance curves. The solvent was totally effective in removing the cigarette stain without changing the color of the silicone base.

J Dent Res 62(7):853-855, July 1983

Introduction.

Maxillofacial prostheses are used to treat patients with oral-facial defects, to enable patients to return to an active role in society. However, in service, staining has been found to be a major cause of discoloration of maxillofacial prostheses ${ }^{1}$ and may necessitate frequent replacement. This places a financial burden on the patients and taxes the facilities where prostheses are made.

In recent studies, ${ }^{2.3}$ samples of a silicone maxillofacial elastomer stained with lipstick, disclosing solution, and methylene blue were cleaned by solvent extraction using various chemically dissimilar solvt nts. The results demonstrated that solvent extraction vas totally effective in removing those stains. The solve.its caused little or no change in the original colors of the samples, which were previously pigmented with maxillofacial pigments.

Clinical observations suggest that habitual cigarette smoking by a patient can rapidly cause a color change in a prosthesis. The purpose of this study was to determine the quantitative color changes in a maxillofacial elastomer as a result of cigarette smoking in vitro, and to evaluate the effectiveness of solvent extraction in removing this stain.

\section{Materials and methods.}

Silastic $44210^{*}$ was chosen as the base elastomer for cigarette smoke staining. It is a material with proven color and physical property stability under conditions of accelerated aging, 4,5 and it can easily be pigmented and fabricated into a prosthesis. It also has the characteristic of forming a three-dimensional cross-linked network, a quality essential for successful solvent extraction. The solvent selected for removal of the smoke stain was $1,1,1$ trichloroethane because of its low degree of toxicity, ${ }^{6}$ nil carcinogenicity, ${ }^{7}$ and compatibility with Silastic $44210.2,3$

Samples $6 \times 4 \times 0.35 \mathrm{~cm}$ were prepared following the manufacturer's instructions. In order to evaluate the quantitative color change in the elastomer as a function of cigarette exposure, we stained the samples in a smoke chamber as seen in the schematic drawing in Fig. 1. The smoke chamber was made from a large glass desiccator with openings that allowed smoke to be drawn in near the bottom of the chamber and to exit from the top. A magnetic stirrer was used to provide uniform density of the cigarette smoke in the chamber. At the inlet port of the desiccator, a two-way valve was installed with two cigarette

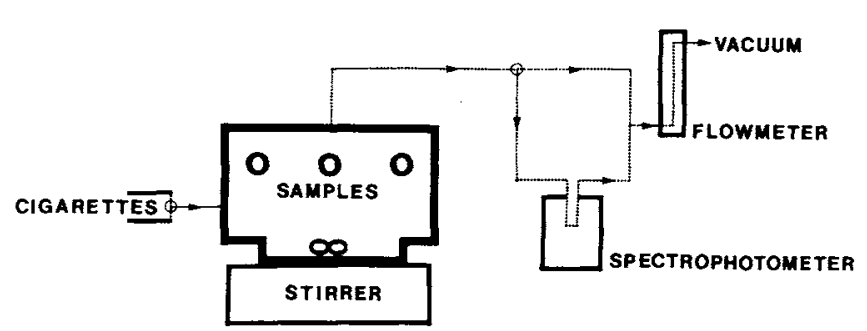

Fig. 1 - Smoke chamber.

holders attached to it. A continuous supply of smoke was supplied to the chamber by alternating the position of the valve and allowing each cigarette to be replaced before it was consumed. A vacuum was applied to the exit port through an inline flowmeter, and the flow of smoke was maintained at $9 \mathrm{cc}$ per s. A two-way valve in the exit line provided a parallel by-pass to a spectrophotometer ${ }^{\dagger}$ with a fixed wavelength of $550 \mathrm{~nm}$. This allowed for periodic monitoring of the smoke density, which was maintained at $71 \%$ transmittance.

Prior to staining with cigarette smoke, we measured the colors of the samples with an uv-visible spectrophotometer and a reflectance sphere. After the colors of the samples were recorded, they were exposed to cigarette smoke in the chamber at a rate of one cigarette per three min. The samples were positioned vertically at the wall of the chamber, with one side of each sample covered so that only one side was exposed to the smoke. Color changes in the samples were evaluated at intervals of ten cigarettes up to a total of 120 . Ivory $\mathrm{Liquid}^{+}$and distilled water were used to clean the surfaces of the samples after each staining interval. Removal of surface stain was done by hand cleaning, followed by rinsing with distilled water. The samples were dried before color measurements were made.

After exposure to the smoke of 120 cigarettes, the samples were solvent-extracted with 1,1,1-trichloroethane for three $d$ to determine whether the smoke stain could be removed. During the extraction process, the samples swell, and, prior to final drying, they are de-swollen by additions of methanol. After de-swelling, the samples were dried to a constant weight under a high vacuum to eliminate all traces of the solvent.

For color analysis, reflectance curves were obtained for each sample at all of the indicated time intervals. A white barium sulphate reference standard was used to back the samples and to calibrate the instrument. The color parameters of luminous reflectance, dominant wavelength, and excitation purity were calculated from the reflectance curves of the samples. The calculations were made relative to the C.I.E. Chromaticity Diagram, $1931^{8}$ and Source A. ${ }^{9}$ Five samples were evaluated at each test condition. The means and standard deviations of the color parameters at each time interval were statistically compared using Student's paired $t$ test at the $95 \%$ confidence level. ${ }^{10}$

\footnotetext{
† Spectronic 20, Bausch \& Lomb, Rochester, NY 14625
}

${ }^{+}$The Procter \& Gamble Co., Cincinnati, OH 45201
Received for publication September 21, 1982

Accepted for publication February 22, 198

* Dow Corning Corp., Midland, MI 48640 
Results.

As seen in Fig. 2, the luminous reflectance of the samples decreased steadily from an average of $80.0(0.7)$ prior to staining to $51.5(0.8)$ after exposure to the smoke of 120 cigarettes. This represents a large change in luminous reflectance, and the samples were badly discolored. There was no statistical difference between the luminous reflectance of the samples after solvent extraction when compared to the samples prior to staining.

The dominant wavelength of the samples increased from $584.9(0.2) \mathrm{nm}$ prior to staining to $588.5(0.1) \mathrm{nm}$ after exposure to the cigarette smoke (see Fig. 3). Following solvent extraction, there was no significant difference in dominant wavelength compared to the dominant wavelength prior to staining.

As seen in Fig. 4, there were considerable changes in excitation purity at all intervals after exposure to the cigarette smoke. The excitation purity increased from $0.082(0.008)$ before staining to $0.722(0.006)$ after staining. This change of 0.64 in excitation purity represents a large increase in color saturation. Following solvent extraction, there was no statistical difference in excitation purity when compared to the samples prior to staining.

\section{Discussion.}

The color parameters of luminous reflectance, dominant wavelength, and excitation purity, determined before staining and after intervals of exposure to the smoke of cigarettes, demonstrated cumulative effects of cigarette smoke in vitro on the color of a silicone maxillofacial elastomer. The use of a surface cleaning agent for removal of surface stain prior to spectrophotometric measurements was essential to ensure that the discoloration of the samples was due only to stain penetration.

The results of color analysis demonstrated that the

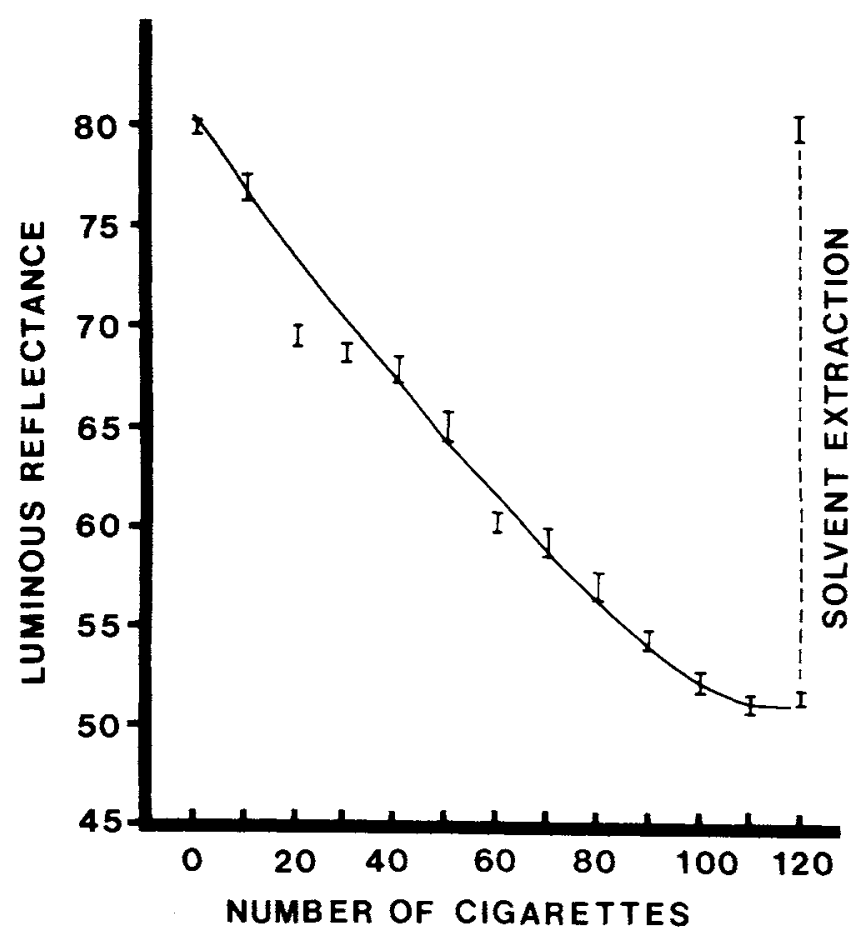

Fig. 2 - Luminous reflectance as a function of smoke stain.

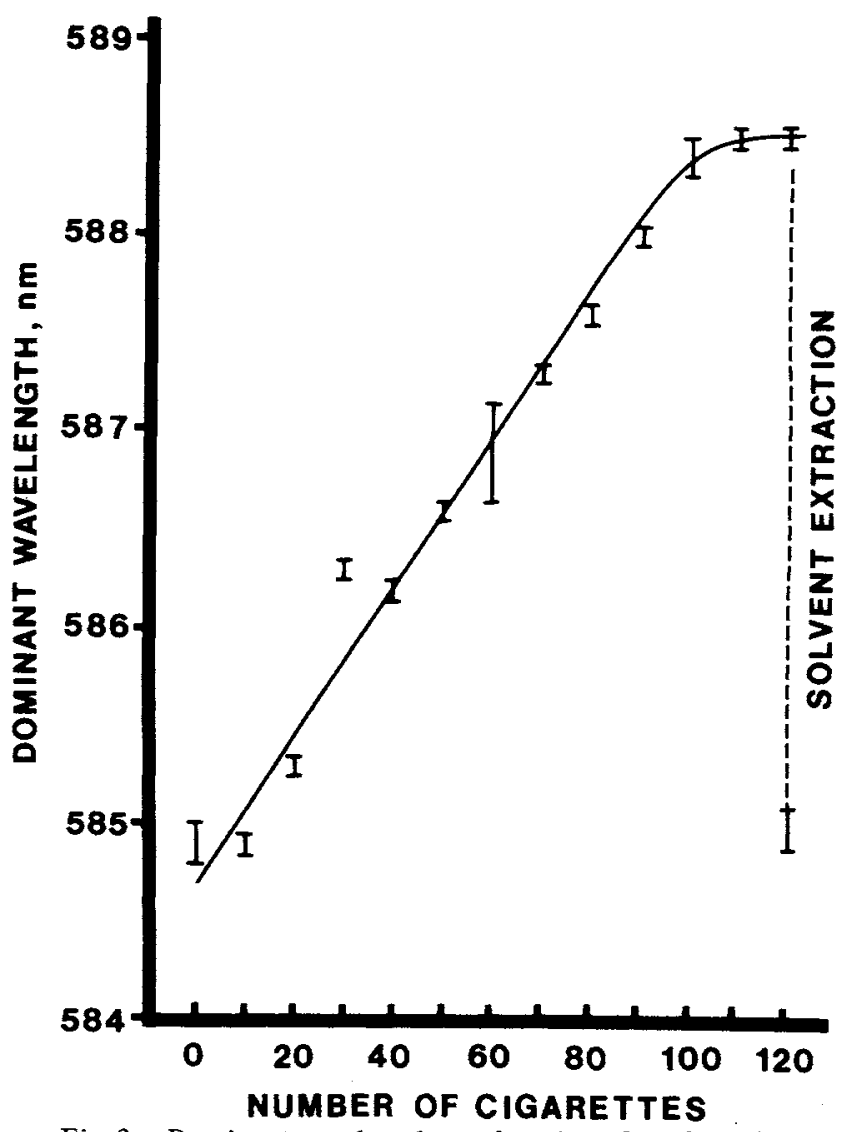

Fig. 3 - Dominant wavelength as a function of smoke stain.

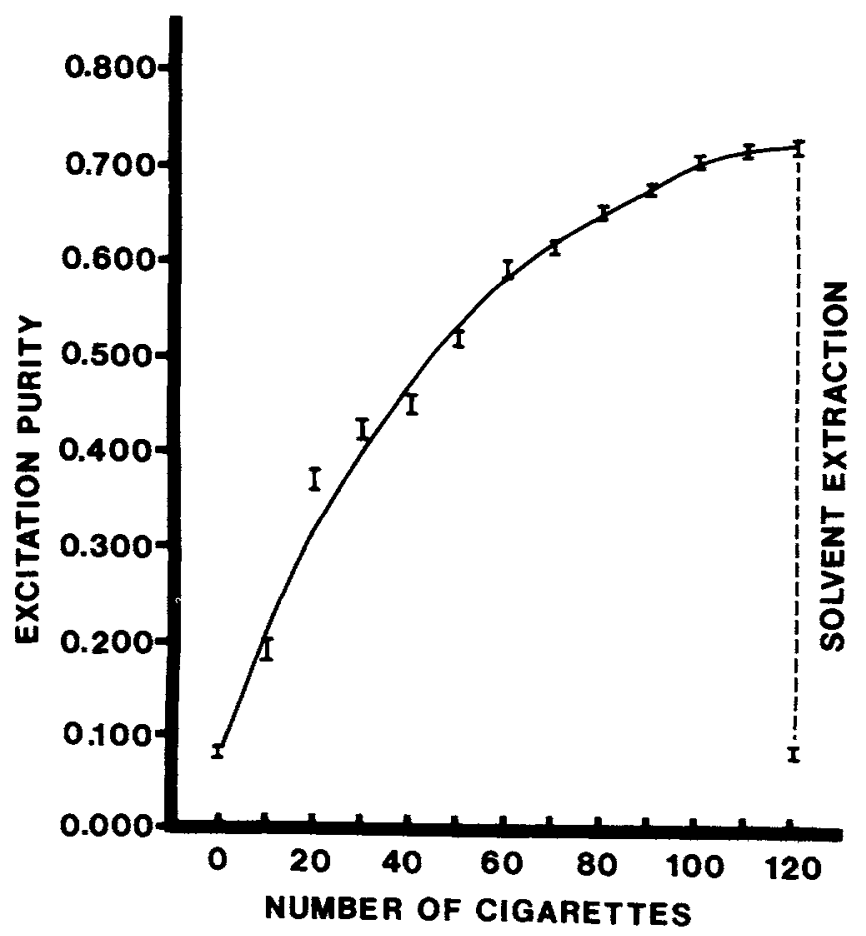

Fig. 4 - Excitation purity as a function of smoke stain.

elastomer became darker, changed slightly in dominant wavelength, and became saturated in color as exposure to cigarette smoke increased. The smoke stain produced a 
color change at all test intervals and reached a plateau after 110 cigarettes. Following staining, the original color parameters of the samples were restored by solvent extraction with 1,1,1-trichloroethane.

\section{Conclusions.}

Cigarette smoke caused large changes in the color of Silastic 44210, an RTV silicone maxillofacial elastomer. $1,1,1$-trichloroethane was totally effective in removing the cigarette stain from the elastomer. This demonstrates the potential of solvent extraction techniques for extending the service life of a maxillofacial prosthesis.

\section{REFERENCES}

1. KORAN, A.; LEPEAK, P.; and CRAIG, R.G.: Stain Resistance of Maxillofacial Materials, $J$ Dent Res 58:1455-1460, 1979.

2. YU, R.; KORAN, A.; RAPTIS, C.N.; and CRAIG, R.G.: Stain Removal from a Silicone Maxillofacial Elastomer, $J$ Dent Res 60:1754-1758, 1981.
3. YU, R.; KORAN, A.; CRAIG, R.G.; and RAPTIS, C.N.: Stain Removal from a Pigmented Silicone Maxillofacial Elastomer, $J$ Dent Res 61:993-996, 1982.

4. YU, R.; KORAN, A.; and CRAIG, R.G.: Physical Properties of Maxillofacial Elastomers Under Conditions of Accelerated Aging, J Dent Res 59:1041-1047, 1980.

5. CRAIG, R.G.; KORAN, A.; YU, R.; and SPENCER, J.: Color Stability of Elastomers for Maxillofacial Appliances, $J$ Dent Res 57:866-871, 1978 .

6. STEWART, R.D.; GAY, H.H.; ERLEY, D.S.; HAKE, C.L.; and SCHAFFER, A.W.: Human Exposure to 1,1,1-trichloroethane Vapor - Relationship of Expired Air and Blood Concentrations to Exposure and Toxicity, Hygiene Assoc J 22:252, 1961.

7. Position Statement/Background Information - 1,1,1-trichloroethane, Dow Corning Corp., March 15, 1979.

8. JUDD, D.B. and WYSZECKI, G.: Color in Business, Science and Industry, New York, N $N_{2}^{*}$ : Wiley \& Sons, Inc., 1975, p. 131.

9. Ibid., pp. 106-108.

10. YOSHIKAWA, H.: A Collection of Procedures for Statistical Analysis, Tokyo, Japan: Nikkagiren Publishing Co., 1974, p. 33 .

\section{Call for Nominees}

\section{Pulp Biology Research Award}

The award was established to recognize, encourage, and stimulate outstanding research contributions in the field of pulp biology. The award is sponsored by the Pulp Biology Group, International Association for Dental Research, and supported by L. D. Caulk Co. It consists of a plaque and cash prize.

The nominee must have contributed significantly to the knowledge in the field of pulp biology through basic or clinical research. The nominee may be a researcher, clinician, teacher, or student, but must be an IADR member. There are no age restrictions. Posthumous nominations are not acceptable.

Any IADR or PBG member may nominate a candidate for the award. The deadline for nominations is December 1 , 1983. After five years the nomination will be withdrawn unless a renomination is received.

The following information must accompany each nomination: complete curriculum vitae, including name, address, date and place of birth, education, honors, employment, membership in professional organizations, publications, and a summary of specific scientific contributions of the candidate. Also essential is a short statement describing the reasons for nominating the individual.

Send nominations and supporting documents to:

\section{Dr. Calvin D. Torneck}

Faculty of Dentistry

University of Toronto

124 Edward Street

Toronto, ON Canada M5G 1 G6 (continued from Inside Front Cover)

\section{Nomination Regulations}

Any IADR member may nominate a candidate for a science award. The deadline for nominations is September 1,1983 . Once a nomination is made, it is considered each year for five years unless the nominee is selected for an award during this period. After the fifth year, the nomination is withdrawn unless a renomination is received.

The following information MUST accompany each nomination:

(1) a short statement describing the reasons you are nominating the individual for the particular award; and

(2) complete curriculum vitae-

(a) name,

(b) address,

(c) date and place of birth,

(d) education,

(e) honors,

(f) employment,

(g) membership in professional organizations,

(h) bibliography, and

(i) summary of specific scientific contributions of the candidate.

Nominations and supporting documents should be sent to:

Dr. Gordon H. Rovelstad,

Chairman, Science Awards Committee,

Suite $352 \mathrm{~N}$,

$7315 \mathrm{~W}$ isconsin Avenue,

Bethesda, MD 20014. 